\title{
Application of Fuzzy Abduction Technique in Aerospace Dynamics
}

\author{
Sudipta Ghosh \\ Department of Electronics and Communication Engineering \\ Calcutta Institute of Engineering and Management \\ Kolkata, India
}

\author{
Souvik Chatterjee \\ Department of Instrumentation and Control Engineering \\ Calcutta Institute of Engineering and Management \\ Kolkata, India
}

\begin{abstract}
The purpose of this paper is to apply Fuzzy Abduction Technique in aerospace dynamical problem. A model of an aeroplane is proposed for consideration at different air density level of the atmosphere and at different speed of the plane. Different air density of the atmosphere, angle of wings and speed of the plane are selected as parameters to be studied. In this paper a method is developed to determine the angle of wings of the plane with respect to its axis at different air density level of the atmosphere and at different speed of the plane. Data are given to justify our proposed method theoretically.
\end{abstract}

Keywords-Fuzzy logic; Fuzzy abduction; Aerospace dynamics; Inverse Fuzzy relation

\section{INTRODUCTION}

Recently a good number of researchers had introduced abduction technique in aerospace dynamical problem. Abduction is an important tool to solve various problem including diagnosis and natural language understanding [4], [ 7] . Also it is applicable in high level reasoning such as hypothetical reasoning [10] and default reasoning [ 3 ]. Pople [ 1 ] bases his discussion of first - order logic and defined abduction as the procedure for derivation of hypothesis which explain a conjecture using an axiom set. Reggia [ 2 ] proposed abduction for diagnosis based on a relation between two sets . Bylander, et.al. [ 8 ] introduced plausibility (a map from the power set of hypothesis to a partially ordered set ) to abduction based on relation. K.Yamade,et.al.[9] studied fuzzy abduction based on multi - valued logic and Y.Tsukamoro [11] has introduced fuzzy logic base on Lukasiewicz logic and its application to diagnosis and control . W.Pedrycz [ 13 ] has investigated numerical and applicational aspect of fuzzy relation equations and henceforth W.pedrycz [ 14 ] has introduced inverse problem in fuzzy relation equation. Afterwards Arnould, et.al.[15] have introduced "if.....then....." rule in case backward - chaining with fuzzy . Bugarin, et.al. [16] have investigated fuzzy reasoning supported by Petri nets. When an aircraft moves through the air it passes through different atmospheric layers. Density

\author{
Binanda Kishore Mondal \\ Department of Instrumentation and Control Engineering \\ Calcutta Institute of Engineering and Management \\ Kolkata, India \\ Debasish Kundu \\ Department of Electronics and Communication Engineering \\ Elite Polytechnic College \\ Kolkata, India
}

varies due to change of atmospheric layers. So the aircraft passes through different air density level. The goal of the present paper is to determine what would be the angle the wings and aircraft velocity to keep constant forward velocity at a certain height of the aircraft for a certain air density level

However, similar problems, as indicated above, in case of application of fuzzy abduction technique in aerospace dynamics have not been invested by any researcher in a similar approach. The authors considered when the air density is low then the speed of the aeroplane and angle of the wings are high and if air density is high the speed of the aeroplane and angle of the wings are low. If medium density of air is considered the speed of the aeroplane and angle of the wings are medium. Despite of importance of inference the concept has no standard definition.

In this paper authors propose a fuzzy abduction [18-23] method in aerospace dynamics. At first authors investigated modus pones and modus tolens in specific situation and showed that the inferred results were obtained as a truth value. Then the concept of derivation, fuzzy explanation and fuzzy abduction are introduced based on inference. Furthermore, the authors discussed necessary and sufficient conditions for the existence of fuzzy explanation and proposed a procedure to obtain approximate solution when the conditions are not satisfied.

In fine, the authors have illustrated this method by numerical examples.

\section{DETERMINATION OF WING ANGLE AND SPEED USING FUZZY ABDUCTION}

When an aircraft moves through the air, it propagates through different air density level because the atmospheric layers are changing. Suppose, at takeoff region the flight velocity is $\omega \mathrm{Km} / \mathrm{m}$ and air density level is medium. For this situation both the wings of the aircraft are at $90^{\circ}$ from the axis of its body, shown in fig. 


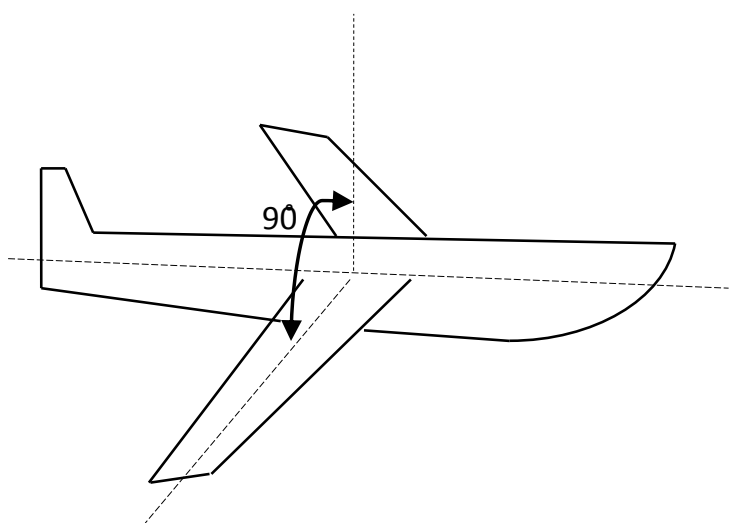

Fig. 1. Both the wings of the aircraft are perpendicular $\left(90^{\circ}\right)$ from the axis of its body

If the aircraft moves from this medium air density level to a lower air density level, it will moves down and the forward velocity will be decreased. To balance the height of the aircraft from the earth surface, the wings should be kept down to block more air and to develop a downward thrust so as to prevent the aircraft from moving down. Hence, both the wings of the aircraft should have an obtuse angle (i.e., $>90^{\circ}$ ) from the axis of its body, shown in fig.B

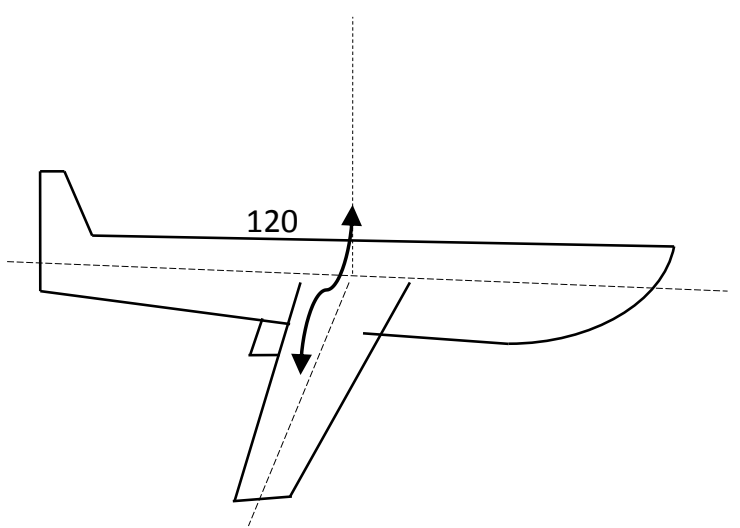

Fig. 2. Both the wings of the aircraft are at $120^{\circ}$ angle from the axis of its body

On the other hand, if the aircraft moves from the medium air density level to a higher air density level, it will move upward and the forward velocity will be decreased. To balance the height of the aircraft from the earth surface, the wings should be kept up to pass more air and to release air thrust so as to prevent the aircraft from moving upward. Hence, both the wings of the aircraft should have an acute angle (i.e., < $90^{\circ}$ ) from the axis of its body, shown in fig.C.

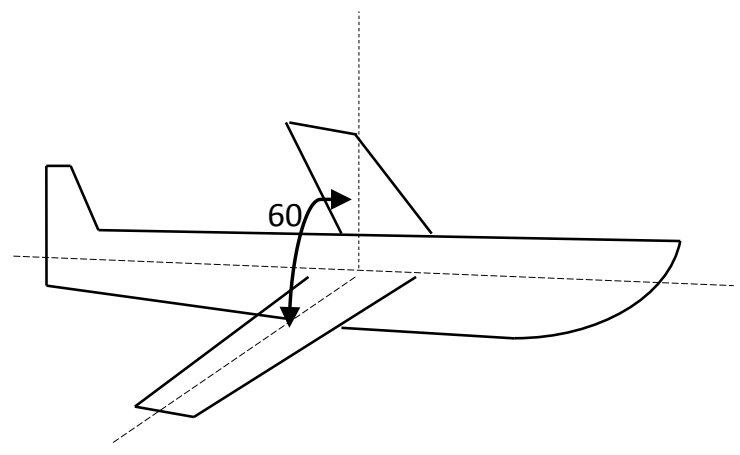

Fig. 3. Both the wings of the aircraft are at $60^{\circ}$ angle from the axis of its body

\section{RESULTS}

From above discussion, we refer the problem as, what would be wings angle and aircraft velocity to keep constant forward velocity and the height of the aircraft for a certain air density level? To solve this problem it is needed to know about the relationship between the wings angle and air density level, and also the aircraft velocity and air density level. For that we set 6 fuzzy rules which are given below.

Rule 1: If wings angle is HIGH, air density will be LOW.

Rule 2: If speed is HIGH, air density will be LOW.

Rule 3: If speed is MEDIUM, air density will be MEDIUM.

Rule 4: .If speed is LOW, air density will be HIGH.

Rule 5: If wings angle is MEDIUM, air density will be MEDIUM

Rule 6: If wings angle is LOW, then air density will be HIGH.

Now, fuzzy membership curves for speed, wings angle and air density are defined. 


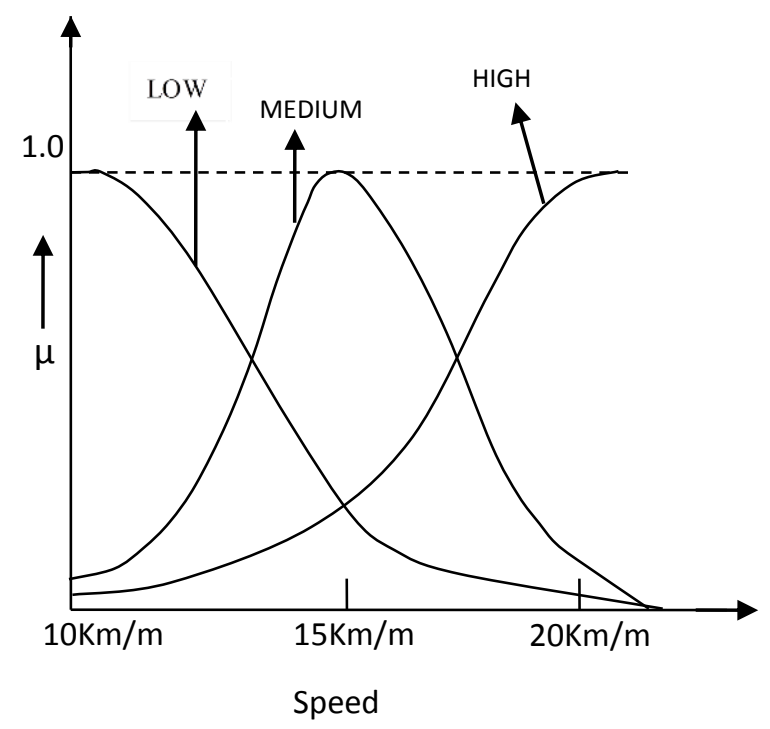

Fig. 4. Membership distribution curves of speed as LOW, MEDIUM and HIGH

From membership curve of speed we define LOW_SPEED, MEDIUM_SPEED and HIGH_SPEED as,

$10 \mathrm{Km} / \mathrm{m} 15 \mathrm{Km} / \mathrm{m} 20 \mathrm{Km} / \mathrm{m}$
LOW_SPEED =
$[1.0$
0.5
$0.2]$

$10 \mathrm{Km} / \mathrm{m} 15 \mathrm{Km} / \mathrm{m} 20 \mathrm{Km} / \mathrm{m}$

$\left.\begin{array}{lll}\text { MEDIUM_SPEED }=[0.1 & 1.0 & 0.2\end{array}\right]$

HIGH_SPEED $=\quad\left[\begin{array}{lll}0.1 & 0.5 & 1.0\end{array}\right]$.

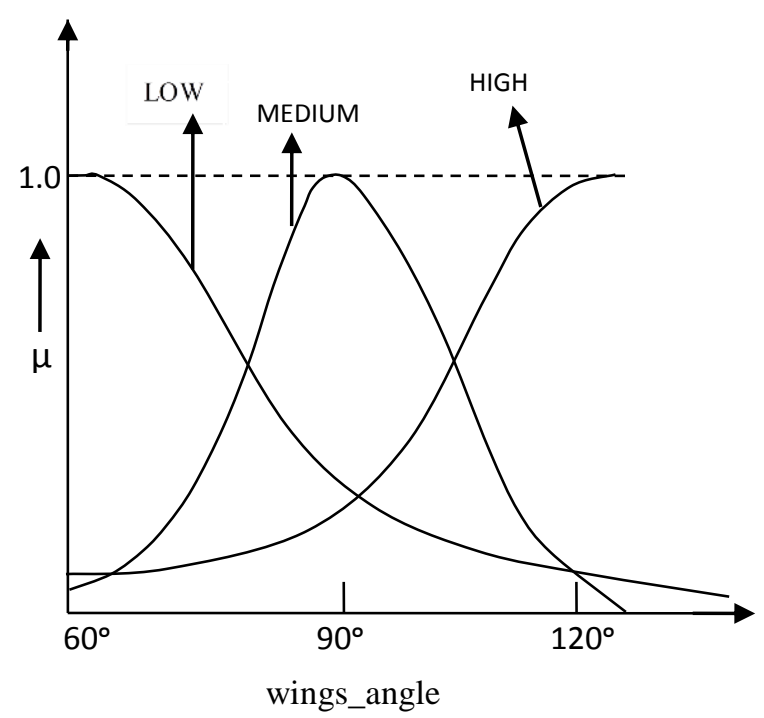

Fig. 5. Membership distribution curves of wings_angle as LOW, MEDIUM and HIGH
From membership curve of wings_angle we define LOW_WINGS_ANGLE, MEDIUM_WINGS_ANGLEand HIGH_WINGS_ANGLE as,

$60^{\circ} \quad 90^{\circ} \quad 120^{\circ}$

LOW_WINGS_ANGLE $=\left[\begin{array}{lll}1.0 & 0.5 & 0.1\end{array}\right]$

$60 \quad 90^{\circ} \quad 120^{\circ}$

MEDIUM_WINGS_ANGLE=[0.1 $0.1 \quad 0.1]$

$60^{\circ} \quad 90^{\circ} \quad 120^{\circ}$

HIGH_WINGS_ANGLE $=\left[\begin{array}{lll}0.2 & 0.4 & 1.0\end{array}\right]$.

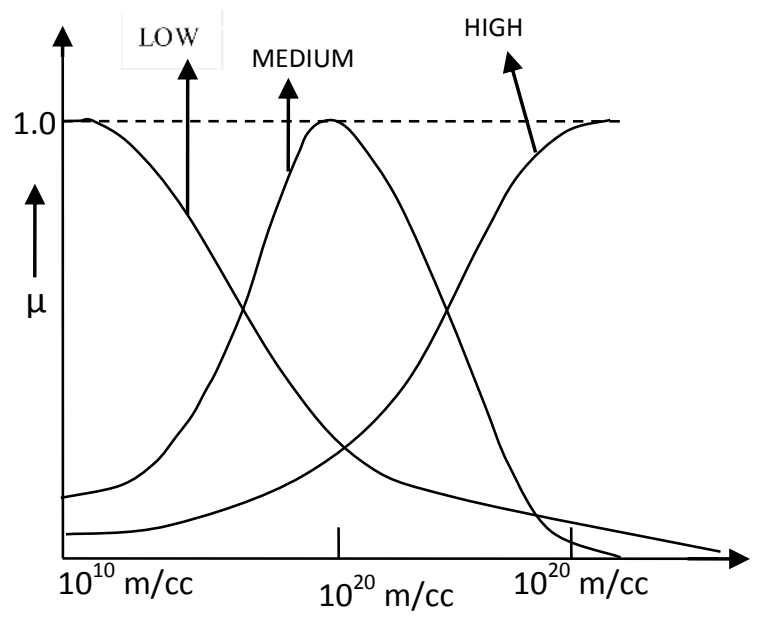

air_density

Fig. 6. Membership distribution curves of air density as LOW, MEDIUM and HIGH

From membership curve of air_denity we define LOW_AIR_DENSITY, MEDIUM_AIR_DENSITY and HIGH_AIR_DENSITY as,

LOW_AIR_DENSITY=

$10^{10} \mathrm{~m} / \mathrm{cc} 10^{20} \mathrm{~m} / \mathrm{cc} 10^{30} \mathrm{~m} / \mathrm{cc}$

$\left[\begin{array}{lll}1.0 & 0.5 & 0.1\end{array}\right]$

MEDIUM_AIR_DENSITY=

$10^{10} \mathrm{~m} / \mathrm{cc} 10^{20} \mathrm{~m} / \mathrm{cc} 10^{30} \mathrm{~m} / \mathrm{cc}$

$\left[\begin{array}{lll}0.1 & 1.0 & 0.3\end{array}\right]$

HIGH_AIR_DENSITY=

$10^{10} \mathrm{~m} / \mathrm{cc} 10^{20} \mathrm{~m} / \mathrm{cc} 10^{30} \mathrm{~m} / \mathrm{cc}$

$\left[\begin{array}{lll}0.1 & 0.6 & .01\end{array}\right]$

For Rule 1, using Mamdani's implication, we construct relational matrix $\mathrm{R}_{2}$ as,

$$
\begin{aligned}
\mathrm{R}_{1} & =\left(\mathrm{HIGH} \_ \text {WINGS_ANGLE }\right)^{\mathrm{T}} \mathrm{o}\left(\mathrm{LOW} \_\mathrm{AIR} \_\mathrm{DENSITY}\right) \\
& =\left[\begin{array}{lll}
0.2 & 0.4 & 1.0
\end{array}\right]^{\mathrm{T}} \mathrm{o}\left[\begin{array}{lll}
1.0 & 0.5 & 0.1
\end{array}\right]
\end{aligned}
$$




$$
=\left[\begin{array}{lll}
0.2 & 0.2 & 0.1 \\
0.4 & 0.4 & 0.1 \\
1.0 & 0.5 & 0.1
\end{array}\right] .
$$

For Rule 2, using Mamdani's implication, we construct relational matrix $\mathrm{R}_{1}$ as,

$$
=\left[\begin{array}{lll}
0.1 & 0.1 & 0.1 \\
0 . .5 & 0.5 & 0.1 \\
1.0 & 0.5 & 0.1
\end{array}\right] \text {. }
$$$$
\mathrm{R}_{2}=(\text { HIGH_SPEED })^{\mathrm{T}} \mathrm{o}(\text { LOW_AIR_DENSITY })
$$$$
=\left[\begin{array}{lll}
0.1 & 0.5 & 1.0
\end{array}\right]^{\mathrm{T}} \text { o }\left[\begin{array}{lll}
1.0 & 0.5 & 0.1
\end{array}\right]
$$

For Rule 3, using Mamdani's implication, we construct relational matrix $\mathrm{R}_{3}$ as,

$$
\begin{aligned}
\mathrm{R}_{3} & =(\text { MEDIUM_SPEED })^{\mathrm{T}} \mathrm{O}(\text { MEDIUM_AIR_DENSITY }) \\
& =\left[\begin{array}{lll}
0.1 & 1.0 & 0.2
\end{array}\right]^{\mathrm{T}} \mathrm{o}\left[\begin{array}{lll}
0.1 & 1.0 & 0.3
\end{array}\right] \\
& {\left[\begin{array}{lll}
0.1 & 0.1 & 0.1 \\
0.1 & 1.0 & 0.3 \\
0.1 & 0.2 & 0.2
\end{array}\right] . }
\end{aligned}
$$

For Rule 4, using Mamdani's implication, we construct relational matrix $\mathrm{R}_{5}$ as,

$$
\begin{aligned}
\mathrm{R}_{4}= & (\text { LOW_SPEED })^{\mathrm{T}} \mathrm{o}(\text { HIGH_AIR_DENSITY }) \\
= & {\left[\begin{array}{lll}
1.0 & 0.5 & 0.2
\end{array}\right]^{\mathrm{T}} \mathrm{o}\left[\begin{array}{lll}
0.1 & 0.6 & 1.0
\end{array}\right] } \\
& {\left[\begin{array}{lll}
0.1 & 0.6 & 1.0 \\
0.1 & 0.5 & 0.5 \\
0.1 & 0.2 & 0.2
\end{array}\right] . }
\end{aligned}
$$

For Rule 5, using Mamdani's implication, we construct relational matrix $\mathrm{R}_{4}$ as,

$\mathrm{R}_{5}=(\text { MEDIUM_WINGS_ANGLE })^{\mathrm{T}} \mathrm{o}($ MEDIUM_AIR_DE NSITY)

$$
=\left[\begin{array}{lll}
0.1 & 0.1 & 0.1 \\
0.1 & 1.0 & 0.3 \\
0.1 & 0.1 & 0.1
\end{array}\right] \text {. }
$$$$
=\left[\begin{array}{lll}
0.1 & 1.0 & 0.1
\end{array}\right]^{\mathrm{T}} \mathrm{o}\left[\begin{array}{lll}
0.1 & 1.0 & 0.3
\end{array}\right]
$$

For Rule 6, using Mamdani's implication, we construct relational matrix $\mathrm{R}_{6}$ as,

$$
\begin{aligned}
\mathrm{R}_{6} & =(\text { LOW_WINGS_ANGLE })^{\mathrm{T}} \mathrm{o}\left(\mathrm{HIGH} \_ \text {AIR_DENSITY }\right) \\
& =\left[\begin{array}{lll}
1.0 & 0.5 & 0.1
\end{array}\right]^{\mathrm{T}} \mathrm{o}\left[\begin{array}{lll}
0.1 & 0.6 & 1.0
\end{array}\right]
\end{aligned}
$$

$$
=\left[\begin{array}{lll}
0.1 & 0.6 & 1.0 \\
0.1 & 0.5 & 0.5 \\
0.1 & 0.1 & 0.1
\end{array}\right] .
$$

Now, say air density is $10^{25} \mathrm{~m} / \mathrm{cc}$, thus using $\alpha$-cut we have LOW_AIR_DENSITY=

$($ LOW_AIR_DENSITY $) \wedge 0.2=\left[\begin{array}{lll}0.2 & 0.2 & 0.1\end{array}\right]$

$$
\text { MEDIUM_AIR_DENSITY= }
$$

(MEDIUM_AIR_DENSITY) $\wedge 0.5=\left[\begin{array}{lll}0.1 & 0.5 & 0.3\end{array}\right]$

$$
\begin{aligned}
& \text { HIGH_AIR_DENSITY }=\quad(\text { HIGH_AIR_DENSITY }) \wedge 0.8 \\
& =\left[\begin{array}{lll}
0.1 & 0 . \overline{6} & 0.8
\end{array}\right]
\end{aligned}
$$

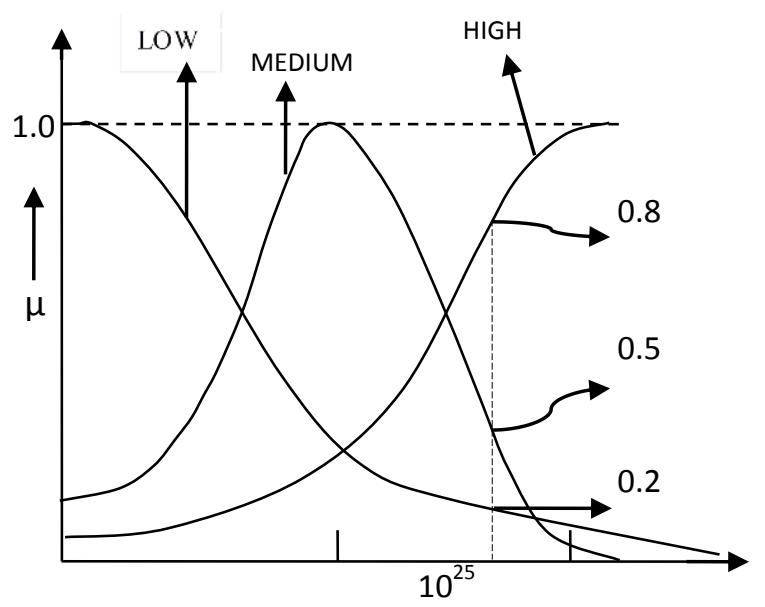

air_density

Fig. 7. $\alpha$-cut for air density of $10^{25} \mathrm{~m} / \mathrm{cc}$

$$
\begin{aligned}
& \text { HIGH_SPEED }=(\text { LOW_AIR_DENSITY }) \mathrm{o}\left(\mathrm{R}_{2}\right)^{-1} \\
& =\left[\begin{array}{lll}
0.2 & 0.2 & 0.2
\end{array}\right] \mathrm{o}\left[\begin{array}{lll}
0.1 & 0.5 & 1.0 \\
0.1 & 0.5 & 0.5 \\
0.1 & 0.1 & 0.1
\end{array}\right] \\
& =\left[\begin{array}{lll}
0.1 & 0.2 & 0.2
\end{array}\right] .
\end{aligned}
$$

1

MEDIUM_SPEED $=($ MEDIUM_AIR_DENSITY $)$ o $\left(\mathrm{R}_{3}\right)^{-}$

$$
=\left[\begin{array}{lll}
0.2 & 0.5 & 0.1
\end{array}\right] \circ\left[\begin{array}{lll}
0.1 & 0.1 & 0.1 \\
0.1 & 1.0 & 0.2 \\
0.1 & 0.3 & 0.2
\end{array}\right]
$$$$
=\left[\begin{array}{lll}
0.1 & 0.5 & 0.2
\end{array}\right] \text {. }
$$

LOW_SPEED $=\left(\mathrm{HIGH} \_A I R \_D E N S I T Y\right) o\left(\mathrm{R}_{4}\right)^{-1}$ 


$$
=\left[\begin{array}{lll}
0.1 & 0.5 & 0.8
\end{array}\right] \text { o }\left[\begin{array}{lll}
0.1 & 0.1 & 0.1 \\
0.6 & 0.5 & 0.2 \\
1.0 & 0.5 & 0.2
\end{array}\right]
$$

$=\left[\begin{array}{lll}0.8 & 0.5 & 0.2\end{array}\right]$.

Hence, the membership distribution of speed = $($ HIGH_SPEED $) \cup($ MEDIUM_SPEED $) \cup($ LOW_SPEED $)$

$=\left[\begin{array}{lll}0.1 & 0.2 & 0.2\end{array}\right] \cup\left[\begin{array}{lll}0.1 & 0.5 & 0.2\end{array}\right] \cup\left[\begin{array}{lll}0.8 & 0.5 & 0.2\end{array}\right]$

$=\left[\begin{array}{lll}0.8 & 0.5 & 0.2\end{array}\right]$.

Thus the speed

$=(0.8 \times 10+0.5 \times 15+0.2 \times 20) /(0.8+0.5+0.2)=13 \mathrm{Km} / \mathrm{m}$. $\left(\mathrm{R}_{1}\right)^{-1}$

HIGH_WINGS_ANGLE $=($ LOW_AIR_DENSITY $) \quad 0$

$$
=\left[\begin{array}{lll}
0.2 & 0.2 & 0.2
\end{array}\right] \text { o }\left[\begin{array}{lll}
0.2 & 0.4 & 1.0 \\
0.2 & 0.4 & 0.5 \\
0.1 & 0.1 & 0.1
\end{array}\right]
$$

$=\left[\begin{array}{lll}0.2 & 0.2 & 0.2\end{array}\right]$.

MEDIUM WINGS ANGLE $=$ (MEDIUM_AIR_DENSITY) $\mathrm{o}\left(\mathrm{R}_{5}\right)^{-1}$

$$
=\left[\begin{array}{lll}
0.2 & 0.5 & 0.1
\end{array}\right] \text { o }\left[\begin{array}{lll}
0.1 & 0.1 & 0.1 \\
0.1 & 1.0 & 0.1 \\
0.1 & 0.3 & 0.1
\end{array}\right]
$$

$=\left[\begin{array}{lll}0.1 & 0.5 & 0.1\end{array}\right]$.

$\left(\mathrm{R}_{6}\right)^{-1}$

LOW_WINGS_ANGLE $=$ (HIGH_AIR_DENSITY $)$ o

$$
=\left[\begin{array}{lll}
0.1 & 0.5 & 0.8
\end{array}\right] \text { o }\left[\begin{array}{lll}
0.1 & 0.1 & 0.1 \\
0.6 & 0.5 & 0.1 \\
1.0 & 0.5 & 0.1
\end{array}\right]
$$

$=\left[\begin{array}{lll}0.8 & 0.5 & 0.1\end{array}\right]$.

Hence, the membership distribution of wings_angle

$=$

$($ HIGH_WINGS_ANGLE) $\cup($ MEDIUM_WINGS_ANGLE) $\cup($ LOW_WINGS_ANGLE)

$=\left[\begin{array}{lll}0.1 & 0.2 & 0.2\end{array}\right] \cup\left[\begin{array}{lll}0.1 & 0.5 & 0.1\end{array}\right] \cup\left[\begin{array}{lll}0.8 & 0.5 & 0.1\end{array}\right]$

$=\left[\begin{array}{lll}0.8 & 0.5 & 0.2\end{array}\right]$.

Thus the wings' angle

$$
=\left(0.8 \times 60^{\circ}+0.5 \times 90^{\circ}+0.3 \times 120^{\circ}\right) /(0.8+0.5+0.3)=78^{\circ}
$$

\section{CONCLUSION}

In Fuzzy Abduction technique, when we consider Aerospace Dynamics problem we faced several
uncertainities.In this case,we consider when the plane goes through different layers we can see several changes have been occurred. Consider all of these problems we consider here fuzzy abduction method.

When the air density varied from low to high then the angle of wings also changed with the speed. wings angle and aircraft velocity to keep constant forward velocity and the height of the aircraft for a certain air density level we follow several rules of fuzzy abduction. From our simulation results we can calculate the wing's angle at different atmosphere.

\section{ACKNOWLEDGEMENT}

We are grateful to our college and friends at Calcutta Institute of Engineering and Management Kolkata,and sincere thanks to our principal Prof.(Dr.) Sibamay Dasgupta, who directly or indirectly is involved in the preparation of this paper.

\section{REFERENCES}

[1] D. Dubois and H. Prade, "Fuzzy sets and Systems: Theory and Applications," Academic press, NY, 1980.

[2] G. J. Klir and B. Yuan, "Fuzzy Sets and Fuzzy Logic: Theory and Applications," Prentice-Hall, NJ, 1995.

[3] W. Pedrycz and F. Gomide, "An Introduction to Fuzzy Sets: Analysis and Design," MIT Press, Cambridge, Massachusetts, 1998.

[4] T. J. Ross, "Fuzzy Logic with Engineering Applications," McGraw-Hill, NY, 1991.

[5] M. Togai and H. Watanabe, "Expert system on a chip: An engine for real time approximate reasoning," IEEE Expert, pp. 55-62, Fall 1986.

[6] L. A. Zadeh, "Fuzzy sets," Information and Control, vol. 8, pp. 338-353, 1965.

[7] H. J. Zimmermann, "Fuzzy Set Theory and Its Applications," Kluwer Academic, Dordrecht, The Netherlands, 1991.

[8] J. M. Mendel, R. I. Jhon, and F. Liu, "Interval Type-2 Fuzzy Logic System Made Simple," IEEE Trans. on Fuzzy Systems, vol. 14, pp. 808821, no. 6, December 2006.

[9] J. M. Mendel, and H. Wu, "Type-2 Fuzzistics for Symmetric Interval Type-2 Fuzzy Sets: Part 1, Forward Problems," IEEE Trans. on Fuzzy Systems, vol. 14, pp. 781-792, no. 6, December 2006.

[10] J. M. Mendel, and H. Wu, "Type-2 Fuzzistics for Nonsymmetric Interval Type-2 Fuzzy Sets: Forward Problems," IEEE Trans. on Fuzzy Systems, vol. 15, pp. 916-930, no. 5, October 2007.

[11] T. Arnould, et al.: Backward-chaining withfuzzy "if... then..." rules, Proc. $2^{\text {nd }} I E E E$ Inter. Conf. Fuzzy Systems, pp. 548-553 (1993).

[12] T. Arnould and S.Tano, "Interval-valued fuzzy backward reasoning," IEEE Trans, Fuzzy Systems, vol 3, no. 4, pp. 425-437, 1995.

[13] B. El Ayeb et al., "A New Diagnosis Approach by Deduction and Abduction," Proc. Int'l Workshop Expert Systems in Eng., 1990.

[14] R. Bhatnagar, L.N. Kanal, "Structural and Probabilistic Knowledge for Abductive Reasoning", IEEE Trans on Pattern Analysis and machine Intelligence, vol. 15 no. 3, pp. 233-245,March 1993

[15] C. Boutillier and V. Becher, "Abduction as Belief Revision," Artificial Intelligence, vol. 77, pp. 43-94, 1995.

[16] T.Bylander,et.al.: The computational complexity of abduction, Artificial Intelligence, Vol.49, pp.25-60 (1991).

[17] Luis M. de Campos, José A. Gámez, and Serafín Moral, "Partial Abductive Inference in Bayesian Belief Networks-An Evolutionary Computation Approach by Using Problem-Specific Genetic Operators", IEEE Transactions On Evolutionary Computation, VOL. 6, NO. 2, APRIL 2002.

[18] S. Chakraborty, S. Gosh, A. Konar, S. Das and R. Janarthanan, "Extraction of Facial Features Based on Emotion using Fuzzy AbductiveReasoning",Smart andTechnologies, Volume27,pp 385-392,June 2014.
Innovation, Systems 
[19] S. Ghosh, G. Paul, A. Dutta and S. Ghosh, "Emotion Detection using Fuzzy Logic" Journal of Mechanics of Continua And Mathematical Sciences, vol.8,no.1,pp 1147-1165, July2013.

[20] S.Ghosh,A.Dutta,S.Roychowdhury,G.Paul, "Weather Prediction by the use of Fuzzy Logic".Journal of Mechanics of Continua And MathematicalSciences, vol.8,no.2,pp 1228-1241, January.2014.

[21] S. Ghosh,A. Dutta, "Fault Detection Technique of Electronic Gadgets using Fuzzy Petrinet Abduction method".Journal of Mechanics of Continua And Mathematical Sciences, vol.9,no.1,pp 1264-1277, July 2014.
[22] S. Ghosh , N Das, D Kundu, G Paul "Fault Detection in Engineering Application using Fuzzy Petrinet and Abduction Technique" Journal of Mechanics of Continua And Mathematical Sciences(ISSN 09738975), vol.9,no.2,pp 1368-1376, January 2015.

[23] S Ghosh, G Paul, "A Type-2 Approach in Emotion Recognition and an Extended Type-2 Approach for Emotion Detection”. Fuzzy Information and Engineering Fuzzy, vol 7,issu 4, pp.475-498 2015. 